EESTI NSV TEADUSTE AKADEEMIA TOIMETISED. 19. KÖIDE.

KEEMIA * GEOLOOGIA. 1970, NR. 3

ИЗВЕСТИЯ АКАДЕМИИ НАУК ЭСТОНСКОН ССР. ТОМ 19

ХИМИЯ * ГЕОЛОГИЯ. 1970, № 3

ВЕРА ПУНГА, А. ФОМИНА, З. ДЕГТЕРЕВА, ВНЛЬЯ ПАЛУ

\title{
К ВОПРОСУ О ХИМИЧЕСКОЙ ПРИРОДЕ СОСТАВЛЯЮЩИХ СЛАНЦЕВОЕ РОСТОВОЕ ВЕЩЕСТВО
}

Органическое вещество сланца-кукерсита является важным сырьем для народного хозяйства и поэтому изучение его химической природы представляет большой интерес.

Лабораторные исследования по окислительной деструкции керогена кукерсита как щелочным перманганатом калия [1], так и азотной кисло. той и воздухом $\left.{ }^{2}\right]$ показали, что в процессе окисления получается смесь органических веществ, различающихся между собой по величине молекул и составу функциональных групп. Водорастворимая часть представляет собой смесь насыщенных дикарбоновых кислот $\left(\mathrm{C}_{4}-\mathrm{C}_{10}\right)$ и летучих с паром одноосновных кислот $\left(\mathrm{C}_{2}-\mathrm{C}_{8}\right)$.

Нерастворимые в слабокислой среде вязкие и твердые кислоты со средним молекулярным весом в пределах 300-1300 представляли собой более сложные промежуточные продукты расщепления керогена. При доокислении промежуточного продукта последний деструктируется до тех же моно- и дикарбоновых кислот с отщеплением части углерода в виде $\mathrm{CO}_{2}$. При окислительной деструкции азотной кислотой происходит разрыв слабых связей макромолекул керогена и присоединение азотной кислоты в виде различных групп: $\mathrm{NO}_{2}, \mathrm{NO}_{3}$ и др. [ [2].

В результате исследований $\left[{ }^{1-3}\right]$ было установлено, что в продуктах окисления керогена отсутствуют бензолкарбоновые кислоты.

Кроме физико-химических исследований промежуточных продуктов окисления керогена, с ними проводились и биологические опыты. Они показали, что соли полифункциональных кислот обладают биологической активностью и в дозах $0,0001-0,1 \%$ могут быть использованы в качестве стимуляторов роста растений (сланцевое ростовое вещество - СРВ) $\left[{ }^{4,5}\right]$. Это обусловило необходимость более углубленного изучения химическогс состава и строения действующего начала СРВ.

В настоящем сообщении изложены материалы первого законченного этсппа более детального исследования составляющих ПФК - полифунк циональных кислот.

ПФК представляют собой коричневую смолистую массу со специфнческим запахом. Они мало растворимы в воде, частично растворимы в эфире и полностью растворимы в ацетоне и диоксане. ПФК относятся к термолабильным соединениям, при повышенных температурах они разлагаются, что препятствует их разделению на компоненты с более низким. молекулярным весом методом дистилляции.

Қалиевые и натрневые соли ПФҚ хорошо растворимы в воде, а кальциевые и бариевые - частично, это указывает на то, что ПФК неоднородны по своему составу. 
Для исследования были взяты два образца ПФК из опытов 211 и 212 , полученные из концентратов керогена разного срока приготовления, с целью выяснения влияния старения концентратов на состав продуктов окисления керогена. Проба 211 была получена из концентрата, приготов. ленного на опытной установке в 1965 г., а проба 212 - из концентрата, приготовленного в 1968 г.

\section{Әкспериментальная часть}

1. Характеристика ПФК. Содержание влаги и летучих веществ определялось путем высушивания проб в вакуумном шкафу при $60^{\circ} \mathrm{C}$ и давлекии 40-50 мм рт. ст. в течение 3 и с дополнительным высушиванием до постоянного веса. Количество золы определялось сожжением и прокаливанием навески проб в муфельной печи при $825^{\circ}$ в течение 3 с с дополнительным прокаливанием остатка до постоянного веса.

Высушенные пробы ПФК далее подвергались анализам на содержание углерода, водорода, азота и функциональному анализу на кислородсодержащие группы, а также определялся средний молекулярный вес. Содержание углерода и водорода определялось по методу Либиха путем сожжения. Двуокись углерода и вода поглощались безводным перхлоралом магния и аскаритом [6]. Общий азот определялся по Қьельдалю, где в качестве катализатора использовалась смесь металлической ртути, селена и сульфата меди[6]. Азот в форме нитратов, нитритов, азотной кислоты и др. определялся по Деварду [7]. Содержание карбоксильных групп устанавливалось методом потенциометрического титрования с раствором едкого кали на $\mathrm{pH}$-метре $M R 2 / H T 2$ до $\mathrm{pH} 8,5$ (область перехода фенолфталеина). Омыление навески проб проводилось 0,5 н. спиртовым раствором едкого кали при нагревании на кипящей водяной бане с обратным холодильником в течение $2 u$.

Общее содержание гидроксильных групп определялось ацетилированием в среде пиридина при нагревании в течение 2 . Все титрования проводились на рН-метре.

Молекулярный вес ПФК определялся криоскопическим методом с применением термометра сопротивления [8]. Для растворения проб ПФК использовался очищенный диоксан. Очистка диоксана «хч» проводилась кипячением в течение 3 и с металлическим натрием и последующей перегонкой. Для определения молекулярного веса применялась фракция с

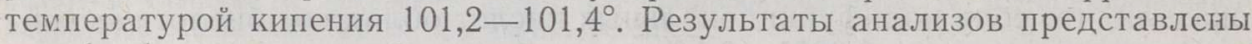
в табл. 1.

Таблица 1

Характеристика исходных проб ПФК

(расчет на сухое вещество)

\begin{tabular}{|c|c|c|c|c|c|c|c|c|c|c|c|}
\hline \multirow{2}{*}{ Проба } & \multirow{2}{*}{$\underset{\%}{\text { Влага, }}$} & \multirow{2}{*}{$\begin{array}{c}\text { Зола, } \\
\%\end{array}$} & \multicolumn{3}{|c|}{$\begin{array}{l}\text { Функциональный } \\
\text { состав. м2 КОН/ट }\end{array}$} & \multicolumn{5}{|c|}{ Элементарный состав, \% } & \multirow{2}{*}{$\begin{array}{c}\text { Средний } \\
\text { молеку: } \\
\text { лярный } \\
\text { вес }\end{array}$} \\
\hline & & & $-\mathrm{COOH}$ & $-\mathrm{CCO}$ & $-\mathrm{OH}$ & $\begin{array}{cc}\text { азот } \\
\text { по } \\
\text { варде- }\end{array}$ & $\left|\begin{array}{cc}\text { азот } \\
\text { по Кье- } \\
\text { льдалю }\end{array}\right|$ & C & $\mathrm{H}$ & $\begin{array}{l}\text { O (по } \\
\text { разно- } \\
\text { сти) }\end{array}$ & \\
\hline
\end{tabular}

$\begin{array}{llllllllllll}211 & 20,8 & 1,9 & 264 & 166 & 84,0 & 2,3 & 4,1 & 59,1 & 7,0 & 29,8 & 821 \\ 212 & 19,9 & 1,7 & 267 & 200 & 79,1 & 2,4 & 3,9 & 59,3 & 7,0 & 29,8 & 826\end{array}$

На основании полученных данных рассчитаны средние эмпирические формулы для обоих образцов ПФК.

Проба $211-\mathrm{C}_{40,43} \mathrm{H}_{57,47} \mathrm{O}_{15,29} \mathrm{~N}_{2,40}$; проба $212-\mathrm{C}_{40,82} \mathrm{H}_{57,82} \mathrm{O}_{15,38} \mathrm{~N}_{2,30}$. 
Средние эмпирические формулы с учетом функциональных групп име. ли следующий вид:

проба $211-\mathrm{C}_{34,13} \mathrm{H}_{52,37} \mathrm{O}_{1,46} \mathrm{~N}_{2,40}(\mathrm{COOH})_{3,87}(\mathrm{OCO})_{2,43}(\mathrm{OH})_{1,23}$; проба $212-\mathrm{C}_{33,93} \mathrm{H}_{52,72} \mathrm{O}_{0,40} \mathrm{~N}_{2,30}(\mathrm{COOH})_{3,94}(\mathrm{OCO})_{2,95}(\mathrm{OH})_{1,16}$.

Отношение $\mathrm{H} / \mathrm{C}$ (атом) для проб 211 и 212 равно 1,85 и $1,88$.

Сравнивая данные табл. 1 и средние эмпирические формулы, можно заметить, что между исследуемыми образцами нет существенной разницы. По составу продукты представляют собой сложного строения оксикарбоновые кислоты, структурные элементы которых связаны между собой сложноэфирными группировками.

2. Фракционирование ПФК. Для более глубокого изучения химической природы ПФК разделялись на фракции последовательным экстрагированием водой, этиловым эфиром и ацетоном.

Водорастворимая фракция получена путем промывания водой пробы ПФК при $50^{\circ}$ с последующей декантацией. Промывные воды вначале были прозрачными, а под конец промывки мутнели. Компоненты ПФК, -бладающие большим сродством к воде, переходили в раствор в виде дисперсионных частиц. Промывание проводилось до исчезновения кислой реакции в промывных водах.

Әкстракт выпаривался в вакууме при 50․ Азотная и другие летучие кислоты улавливались определенным количеством раствора щелочи. Пропускаемый через аппаратуру воздух очищался от $\mathrm{CO}_{2}$.

Нелетучие водорастворимые кислоты высушивались в вакуумном шкафу при $50^{\circ}$ и остаточном давлении $40-50$ мм рт. ст. до постоянного веса. По внешнему виду они представляют собой вязкую массу светлокоричневого цвета. Водорастворимые кислоты хроматографировались методом двухколонной хроматографии на силикагеле по ранее описақному способу [9]. Результаты хроматографирования приведены в табл. 2.

Таблициа 2

Содержание насыщенных дикарбоновых кислот в водорастворимой фракции, \%

\begin{tabular}{|c|c|c|c|c|c|c|c|c|}
\hline Проба & $\mathrm{C}_{4}$ & $\mathrm{C}_{5}$ & $\mathrm{C}_{6}$ & $C_{7}$ & $\mathrm{C}_{8}$ & $C_{9}$ & $C_{10}$ & Сумма \\
\hline 211 & 5,7 & 9,6 & 9,4 & 10,1 & 6,2 & 8,9 & 5,6 & 55,5 \\
\hline 212 & 5,7 & 12,8 & 9,7 & 9,2 & 7,4 & 8,9 & 5,9 & 59,6 \\
\hline
\end{tabular}

Данные хроматографирования показали, что водорастворимая фракция ПФК представляет собой смесь насыщенных дикарбоновых кислот и гешеств неустановленного строения.

Остаток после удаления водорастворимой части экстрагировался этиловым эфиром в аппарате Сокслета. Экстрагирование проводилось при нагревании на водяной бане до получения бесцветного эфирного слоя над патроном. Эфир из полученного экстракта отгонялся, остаток высушивался в вакууме при $50^{\circ}$ до постоянного веса. Полученная фракция представляет собой густую прозрачную вязкую массу красно-коричневого цвета.

Остаток носле извлечения эфиром далее экстрагировался ацетоном на водяной бане до получения бесцветного слоя над патроном. Ацетоновый раствор отфильтровывался от нерастворимых примесей и освобождался от ацетона. Экстракт после отгонки ацетона досушивался в вакууме при $50^{\circ}$ до постоянного веса. Ацетоновый экстракт представляет собой порошок светло-коричневого цвета.

В результате последовательного экстрагирования смесь ПФК распределялась по фракциям, см. табл. 3.

2 ENSV TA Toimetised $\mathrm{K} * \mathrm{G}-31970$ 


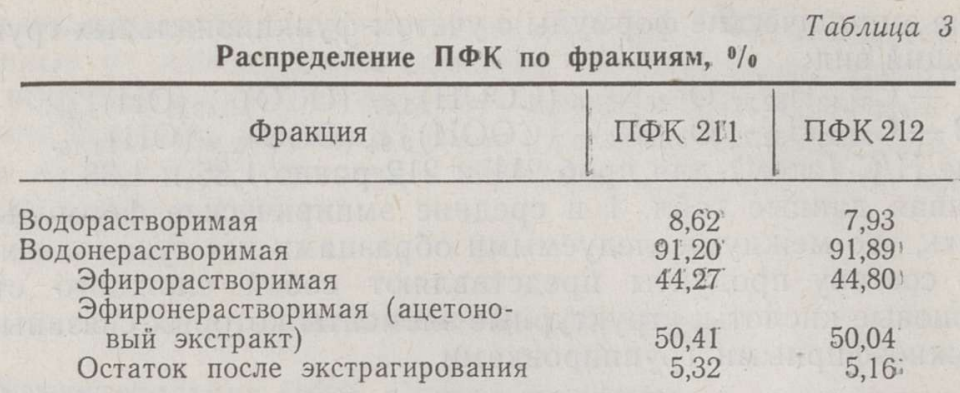

Полученные фракции подвергались анализам на содержание углерода, водорода, азота и функциональному анализу на кислородсодержащие группы, а такље определялся средний молекулярный вес по описанным выше методам для исходных ПФК. Данные анализа представлены в табл. 4.

Сравнивая полученные данные (табл. 4), можно заметить зависимость между увеличением среднего молекулярного веса и усложнением основной структуры: количество усложняющих состав сложноэфирных групп увеличивается.

Из табл. 4 следует, что наименее сложной по составу является водорастворимая фракция. Как показали результаты хроматографированил (табл. 2), она представляет собой смесь насыщенных дикарбоновых кислот $(55-60 \%)$ и веществ неустановленного строения. Очевидно, эти примеси, обладающие большим сродством к воде, экстрагируются вместе с дикарбоновыми кислотами. Количество дикарбоновых кислот не характеризует ПФК, так как они представляют собой часть реакционного раствора, механически удерживаемого вязкой массой ПФК. Опыты показали, что по своему характеру и составу водорастворимая фракция сходна ссоставом сырых дикарбоновых кислот.

Следующей по сложности структуры является эфирорастворимая фракция. Ее средний молекулярный вес почти в 2 раза больше, чем молекулярный вес водорастворимой фракции $(426-460)$, и содержит в свсем составе больше карбоксильных и сложноэфирных групп: соответственно $1,86-2,04$ и $0,81-1,26$. Как показали данные анализа (табл. 4), эфирорастворимая фракция уже по своему характеру - оксикарбоновое соединение, в котором отдельные звенья связаны между собой сложнозфирными группами.

Из полученных фракций наиболее сложна по составу и имеет более высокий средний молекулярный вес - ацетонорастворимая фракция, которая интересна для исследования, так как является более крупным осколком исходной структуры керогена.

Ее средняя эмпирическая формула, рассчитанная на основании данных элементарного и функционального анализов, а также среднего молекулярного веса, имеет следующий вид:

проба $211-\mathrm{C}_{56,60} \mathrm{H}_{86,56} \mathrm{~N}_{1,90}(\mathrm{COOH})_{4,86}(\mathrm{OCO})_{5,97}(\mathrm{OH})_{1,89}\left(\mathrm{NO}_{2}\right)_{2,00}$; проба $212-\mathrm{C}_{57,25} \mathrm{H}_{87,34} \mathrm{~N}_{1,56}(\mathrm{COOH})_{5,16}(\mathrm{OCO})_{5,55}(\mathrm{OH})_{2,03}\left(\mathrm{NO}_{2}\right)_{2,45}$.

Атомарное отношение водорода к углероду в приведенном углеводородном скелете в ацетоновом экстракте равняется $1,82-1,85$.

Полученные данные указывают на известную цикличность структуры или ее ненасыщенность. По данным литературы [10], бромное число для ПФК составляет 2,0-4,0 г Вr/100 г вещества. Недостаток водорода не исчерпывается таким количеством брома, поэтому можно полагать, что показатель ненасыщенности $\mathrm{H} / \mathrm{C}$ характеризует цикличность структуры продукта. 
$\frac{2}{3}$

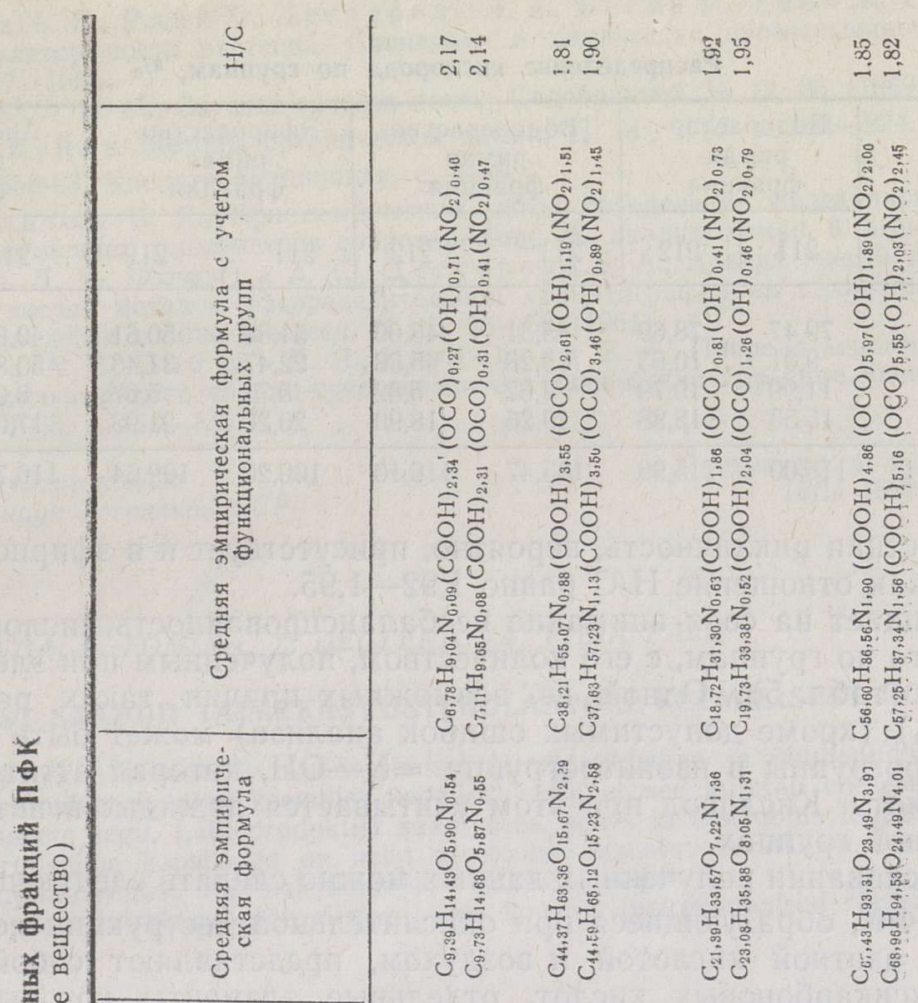

政

วәя ทूเчнdธг

$-\varsigma$ หละOW

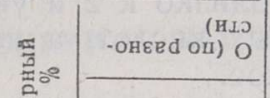

覂憵

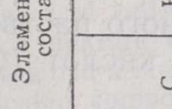

क |

这 Krdeari ou

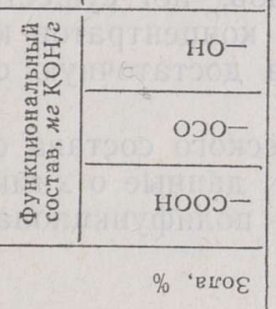

egodע

离
ส্ণ

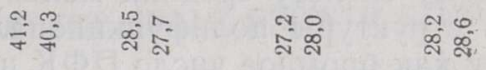

:

के में

कृ

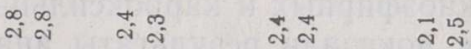

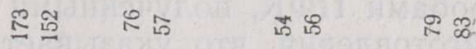

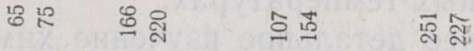

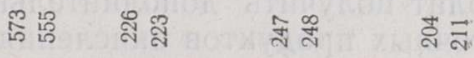

$\stackrel{m}{=} \stackrel{0}{=} 011$ क्ष

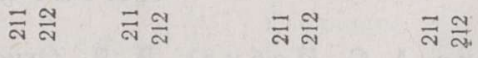

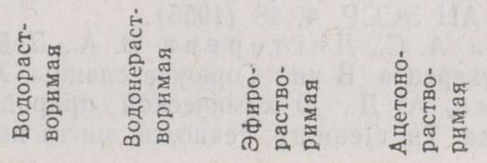


Распределение кислорода по группам, ө/

\begin{tabular}{|c|c|c|c|c|c|c|c|c|}
\hline & \multicolumn{2}{|c|}{$\begin{array}{c}\text { Водораство- } \\
\text { римая } \\
\text { фракция }\end{array}$} & \multicolumn{2}{|c|}{$\begin{array}{c}\text { Водонераство- } \\
\text { римая } \\
\text { фракция }\end{array}$} & \multicolumn{2}{|c|}{$\begin{array}{c}\text { Эфирораство- } \\
\text { римая } \\
\text { фракция }\end{array}$} & \multicolumn{2}{|c|}{$\begin{array}{c}\text { Ацетонораст- } \\
\text { воримая } \\
\text { фракция }\end{array}$} \\
\hline & 211 & 212 & 211 & 212 & 211 & 212 & 211 & 212 \\
\hline $\begin{array}{l}-\mathrm{COOH} \\
-\mathrm{OCO} \\
-\mathrm{OH} \\
-\mathrm{NO}_{2}\end{array}$ & $\begin{array}{r}79,47 \\
9,01 \\
11,99 \\
15,53\end{array}$ & $\begin{array}{l}78,69 \\
10,63 \\
10,79 \\
15,88\end{array}$ & $\begin{array}{r}45,31 \\
33,28 \\
7,62 \\
19,26\end{array}$ & $\begin{array}{r}46,00 \\
45,38 \\
5,82 \\
18,90\end{array}$ & $\begin{array}{r}51,88 \\
22,47 \\
5,71 \\
20,20\end{array}$ & $\begin{array}{r}50,61 \\
31,43 \\
5,67 \\
21,93\end{array}$ & $\begin{array}{r}40,85 \\
50,86 \\
8,03 \\
17,02\end{array}$ & $\begin{array}{r}42,16 \\
45,35 \\
8,29 \\
19,92\end{array}$ \\
\hline Сумма & 116,00 & 115,99 & 105,47 & 116,10 & 100,26 & 109,64 & 116,76 & 115,72 \\
\hline
\end{tabular}

Известная цикличность, вероятно, присутствует и в эфирном экстракте, так как отношение Н/C равно 1,92-1,95.

Обращает на себя внимание несбалансированность кислорода, определенного по группам, с его количеством, полученным при элементарном: анализе (табл. 5). Одной из возможных причин таких расхождений (до 16\%) (кроме допустимых ошибок анализа) может быть изомеризация нитрогруппы в изонитрогруппу $=\mathrm{N}-\mathrm{OH}$, которая оттитровывается как кислота. Қислород при этом учитывается дважды: в нитро- и карбоксильной группах.

На основании полученных данных можно сделать следующие выводы:

1. ПФК, образующиеся при окислительной деструкции керогена кукеғсита азотной кислотой и воздухом, представляют собой сложную смесь оксикарбоновых кислот, отдельные элементы которых связаны слсжноэфирными группами и другими гетероатомными связями.

2. Атомарное отношение водорода к углероду приведенных к углеводородному скелету средних молекул близко к 2 и указывает на цикличность структуры полифункциональных кислот, а не на ненасыщенность, так как бромное число ПФК низкое.

3. Анализами установлено, что водорастворимая фракция представляет собой часть адсорбированного реакционного раствора и в основном состоит из смеси насыщенных дикарбоновых кислот $\left(\mathrm{C}_{4}-\mathrm{C}_{10}\right)$ и сопутствующих им примесей.

4. Наиболее сложна по составу ацетонорастворимая фракция, имею. щая средний молекулярный вес в пределах 1300-1400 и содержащая до 5-6 сложноэфирных и карбоксильных групп.

5. Как показали результаты анализов, нет существенной разницы между пробами ПФК, полученными из концентратов керогена разного срока приготовления, что указывает на достаточную стабильность его при обычных температурах.

6. Более детальное изучение химического состава отдельных фракций позволит получить дополнительные данные о химической природе промежуточных продуктов окисления - полифункциональных кислот.

\section{ЛИ Т Е РА Т У РА}

1. Фомина А. С., Побуль Л. Я., Окислительная деструкция керогена кукерсита. Изв. АН ЭССР 4,48 (1955).

2. Фомина А. С., Д егте рев а 3. А., Действие азотной кислоты на кероген сланца-кукерсита. В кн.: Горючие сланцы. Химия и технология, вып. 2, 1956, с. 7.

3. Кокурин А. Д., О химической природе органической массы прибалтийского сланца. Тр. Ленингр. технолог. ин-та им. Ленсовета, вып. 51, 1959. 
4. Фомина А. С., Р а йг Х., Д ег те р е в а 3. А., В е ски Р., Т и йд Т., Сланщевый стимулятор роста растений. Сланцевая и химическая промышленность, № 1 , $14-17(1966)$.

5. Т р офи мо в Б. М., За счет спящих почек. Садоводство, № 12, 36 (1969).

6. Г убен - В ейл ь, Методы органической химии, II, М., 1967, с. 221-224, 243-248.

7. ГОСТ 10558-63, Кислота адипиновая, с. 4-6.

8. Михкельсон В. Я., Криоскопический метод определения молекулярных весов с применением термометров сопротивления. Ж. аналит. химии, 9, вып. 1 (1954).

9. Побу ль Л. Я., Фоми н а А. С., Д егтере в а 3. А., Анализ смесей дикарбоновых кислот методом распределительной хроматографии на силикагеле. Химия и технология топлив и масел, № 10, 55-59 (1961).

10. Фом ин а А. С., П об уль Л. Я., Д егт ер е а З. А., Природа керогена прибалтийского горючего сланца-кукерсита и его химические сырьевые качества. Таллин, 1965 , с. $134-135$.

\author{
Ннститут химии \\ Академии наук Эстонской ССР
}

Поступила в редакцию

$18 /$ II 1970

VEERA PUNGA, A. FOMINA, Z. DEGTERJOVA, VILJA PALU

\title{
PÕLEVKIVIST SAADUD TAIMEKASVUSTIMULAATORI KEEMILISEST KOOSTISEST
}

Uuriti pōlevkivi kerogeeni oksüdeerimisel lämmastikhappe ja ōhuhapnikuga saadud taimekasvu stimuleeriva aine keemilist koostist. Leiti, et see kujutab enesest polüfunktsionaalsete hapete segu. Lähteproduktist saadi vees, eetris ja atsetoonis lahustuvad fraktsioonid. Keeruliseima koostisega on neist atsetoonis lahustuv fraktsioon. Vees lahustuv fraktsioon kujutab endast dikarboksüülhapete $\left(\mathrm{C}_{4}-\mathrm{C}_{10}\right)$ segu. kulkaal.

Määrati saadud fraktsioonide elementaarne koostis, funktsionaalsed rühmad ja mole-

VEERA PUNGA, A. FOMINA, Z. DEGTERYOVA, VILJA PALU

\section{ABOUT THE CHEMICAL NATURE OF THE SHALE GROWTH STIMULATOR}

The chemical nature of the shale growth stimulator obtained by oxidation of the shale kerogen with nitrogen acid and oxygen was studied. As a result of the study, shale growth stimulator presents a mixture of polyfunctional acids. Fractions soluble in water, ether and acetone were obtained from the stock. The fraction soluble in acetone appeared to be of the mosi complicated composition. The fraction soluble in water is a mixture of dicarboxylic $\left(\mathrm{C}_{4}-\mathrm{C}_{10}\right)$ acids.

The elementary composition of the obtained fractions was determined as well as the composition and molecular weight of functional groups. 